\title{
Post-traumatic high vaginal stricture and hematocolpos impersonating vaginal septum in adolescent girl: a case report
}

\author{
Smeet Patel*, Sanjay Patel, Priyanka Bhadana, Ria Shetty
}

Mayflower Women's Hospital, Ahmedabad, Gujarat, India

Received: 20 January 2022

Accepted: 05 February 2022

\author{
*Correspondence: \\ Dr. Smeet Patel, \\ E-mail: smeet@mayflowerhospital.com
}

Copyright: () the author(s), publisher and licensee Medip Academy. This is an open-access article distributed under the terms of the Creative Commons Attribution Non-Commercial License, which permits unrestricted non-commercial use, distribution, and reproduction in any medium, provided the original work is properly cited.

\begin{abstract}
Vaginal stenosis was once a well-known condition in various nations. Vaginal stenosis can be caused by a variety of factors and manifest in a variety of ways. Because its occurrence is based on misinformation and cultural beliefs, acquired gynaetresia continues to be a major public health concern in underdeveloped nations, despite the fact that it is preventable. Traditional treatment involves an abdomino-perineal approach that requires a laparotomy. We are presenting a rare instance of vaginal stenosis following perineal trauma in an adolescent girl, which resulted in hematocolpos, and also as a novel laparoscopic technique to the management of significant vaginal stenosis.
\end{abstract}

Keywords: Vaginal stenosis, Post-traumatic high vaginal stricture, Hematocolpos

\section{INTRODUCTION}

In today's world, acquired vaginal stenosis is uncommon. Due to cultural customs, acquired gynae-atresia-vaginal stenosis - was once a well-known condition in various nations. ${ }^{1}$ The most common causes of acquired gynaeatresia were chemical vaginitis from the use of caustic vaginal pessaries, secondary to the use of local herb pessaries, and female circumcision. Labial adhesions, or actual adhesions of the vaginal cavity, are uncommon in reproductive-aged women. ${ }^{3}$ However, a vaginal technique cannot be used to remove mid- and high vaginal stenosis without causing harm to the surrounding structures. ${ }^{4}$ Traditional treatment involves an abdomino-perineal approach that necessitates a laparotomy. ${ }^{5}$ We are presenting a rare instance of vaginal adhesion following perineal trauma in an adolescent girl, which resulted in hematocolpos, and also as a novel laparoscopic technique to the management of significant vaginal stenosis.

\section{CASE REPORT}

A 12-year-old girl was sent to our outpatient department (OPD) with primary amenorrhea and cyclical abdominal pain for the past six months. She was involved in a car accident and suffered a perineal injury, requiring vaginal hematoma drainage and perineal repair. There were no previous surgical records available. Her pelvic pain had been becoming worse over time for the past six months, interfering with her daily activities. An abdominopelvic mass measuring 12-14 weeks gravid uterus was discovered during a physical checkup. Her secondary sexual characters had a lot of depth. Under anaesthesia, a vaginoscopy revealed vaginal stenosis with a distal vaginal length of $3 \mathrm{~cm}$, indicating vaginal stenosis. A tight and compressible pelvic mass was discovered during a rectal examination. Hematocolpos with a $10 \times 8 \mathrm{~cm}$ septated collection were discovered on trans-abdominal sonography and magnetic resonance imaging (MRI). The adnexae and other pelvic organs were unremarkable. Both kidneys and spine were confirmed to be normal.

The uterus was normal in size and shape, and the bilateral ovaries were normal on laparoscopy. On the posterior uterine surface and bilateral uterosacral ligaments, there were endometriotic patches. A $3 \mathrm{~cm}$ vaginal endometriotic cyst was found in the left posterolateral upper portion of the vaginal canal. Recto-vaginal dissection was performed 
first, with Denonvillier's fascia, medial para-rectal space protecting hypogastric nerves, and the rectum mobilized down. The bladder was mobilized, and the hematocolpos was drained. A transverse stenosis at the mid-vaginal level was removed. On hysteroscopy, communication between the top and lower parts of the vagina was confirmed. The anterior vaginal wall was sutured in two layers with VLoc no. 1 after vaginoplasty. To keep the vaginal canal open, circumferential sutures were placed around the borders of the septal tissue that had been removed. Check hysteroscopy was done to confirm continuity of vaginal canal. Endometriotic cyst in the vaginal canal was removed with cyst wall in place and sent for histopathological examination (HPE). In-situ vaginal mould was used to prevent stricture and adhesions between the vaginal walls.

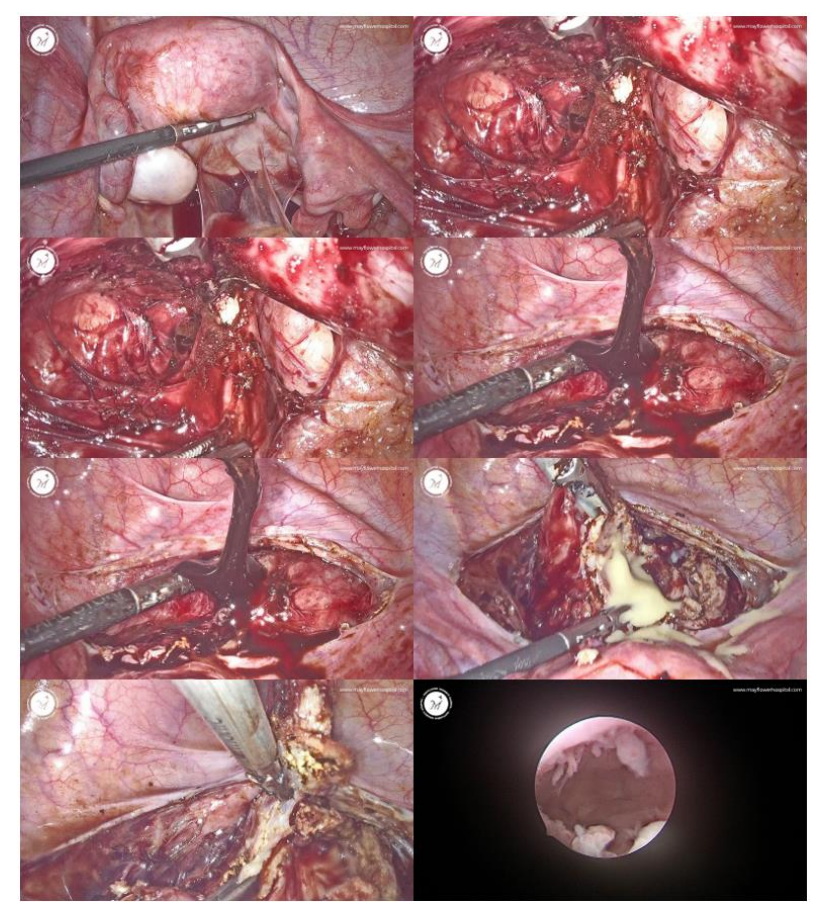

Figure 1: Management vaginal stenosis.

\section{DISCUSSION}

Vaginal stenosis is defined as vaginal shortening and/or decreased width of the vaginal canal. ${ }^{6}$ Vaginal stenosis can be caused by a variety of factors and manifest in a variety of ways. Because its occurrence is based on misinformation and cultural beliefs, acquired gynaetresia continues to be a major public health concern in underdeveloped nations, despite the fact that it is preventable. $^{7}$ The commonest age of detection is 20-30 years. This is the time in a woman's life when she is transitioning from adolescent to family life, with a focus on childbearing in our culture. Acquired gynaetresia prohibits couples from having a satisfying sexual relationship and procreating, resulting in marital discord. As a result, it is a severe gynaecological issue in our environment. ${ }^{8}$
Fowler described a 26-year-old female patient who had a pelvic fracture when she was ten years old. She went to the gynaecological department later because she couldn't have sexual intercourse. Her vaginal stenosis was discovered. Her menstruation was regular, but she had a fistula in her distal vaginal vault. When radiographic and dye investigations were performed, they revealed virtually heterotopic ossification and total vaginal blockage. ${ }^{9}$ After perineal repair surgery, a few patients developed superficial dyspareunia, vulvo-vaginal pain, vaginal stenosis, and a broken or gaping wound, according to Ganapathy et al. A few patients developed superficial dyspareunia, vulvo-vaginal pain, vaginal stenosis, and a broken or gaping wound after perineal repair surgery, according to Ganapathy et al. Although vaginal injuries are uncommon, they necessitate a high level of suspicion. ${ }^{10}$

Because of fibrosis of the vaginal canal, vaginal stenosis can arise as a side effect of radiation therapy. ${ }^{6}$ It usually happens within the first year after being exposed to radiation. Radiation dose, patient age, and lack of vaginal dilator compliance are all risk factors for vaginal stenosis. ${ }^{11}$ It may impair patients' ability to tolerate pelvic examinations required for cancer surveillance in the future, as well as their sexual function and quality of life. ${ }^{12}$

Other techniques for treating subsequent vaginal strictures and stenosis have been tested, despite the fact that our patient was treated surgically. A 14-year-old girl was taken to the hospital with persistent abdominal pain, a case report presented by Betalli et al. ${ }^{13}$ The symptoms had started at menarche (three months ago) and had become more intense each month. She had received treatment for rhabdomyosarcoma when she was two years old. The patients were diagnosed with hematocolpos, hematometra, and hematosalpinx. Drainage with a needle through a vaginoscope helped to reduce acute discomfort. A MRI scan was performed to rule out the possibility of a tumour return. It also confirmed the presence of a hematocolpos. A partially blocking stenosis of the vaginal inlet of about $1 \mathrm{~cm}$ in length was discovered during a vaginal exam. To expand the stricture, dilators were employed, and a stent was left in place for 5 days before being removed. After a month, a second dilatation was performed and Mitomycin$\mathrm{C}$ was given topically due to persistence. After one-month, endoscopic imaging revealed that the stricture had improved, but a submucosal fibrous ring in the vaginal canal remained. Mitomycin-C was given again after three and seven months. The stricture appeared to be getting better. $^{13}$

Yanai et al described a case with other type of management modalities for vaginal stenosis. In the case report, a female patient who was 25 years old and had secondary amenorrhea and dyspareunia. She had secondary amenorrhea as a result of a vaginal outflow restriction. She developed ovarian failure after undergoing bone marrow transplantation for acute myelocytic leukaemia. Oral mucositis developed as a result of the persistent graft versus host reaction. For three years, she was on hormone 
replacement treatment and had regular menses, which eventually stopped and were accompanied by dyspareunia and abdominal discomfort. Ultrasonography of the abdomen revealed hematocolpos. The free drainage was enabled by sonography-guided adhesiolysis of a thick vaginal blockage. A graft-versus-host response was verified by histopathology. Patients with graft-versus-host disease after a bone marrow transplant may get vaginal stricture. Following the operation, high-dose oestrogen medication (later paired with progesterone) was started, as well as regular vaginal dilatations. Hormone-induced menstruation started up again. Dyspareunia faded away with time. ${ }^{14}$

In order to restore anatomy, the optimal moment for perineal repair in any patient is when the main pelvic injury occurs. ${ }^{15}$ However, because our patient was badly injured at the time of presentation and other life-saving surgeries were required, vaginal restoration was not possible. After then, the patient was missing for two years, till she reappeared with complaints of inability to have coitus, which she hadn't had before to the accident. If the condition is discovered by chance, it is critical to consider the patient's age when deciding whether surgery should be conducted. If the patient has no menstrual symptoms or dysmenorrhea and is sexually inactive, it is best to wait until the patient want to become sexually active or plans to conceive, as the risk of restenosis is extremely high. If a surgical or medical procedure is performed on a sexually inactive patient, she must be informed about the importance of using dilators on a regular basis to avoid restenosis. ${ }^{16}$ In our patient, since the fibrous tissue could be removed in totality, rugorosity of the vagina could be released and mucosal approximation was complete we believe that the chances of restenosis are less.

\section{CONCLUSION}

Vaginal stenosis caused by trauma is a rare occurrence, and proper management of original pelvic injury can help prevent it. Active therapy of such instances in the postoperative period, such as the use of dilators or topical creams, or regular sexual intercourse, is critical for preventing restenosis. Regular follow-up appointments are also necessary to detect and prevent restenosis.

\section{Funding: No funding sources}

Conflict of interest: None declared

Ethical approval: Not required

\section{REFERENCES}

1. Kunwar S, Khan T, Gupta H. Acquired gynatresia. BMJ Case Rep. 2014;bcr2014203529.

2. Kaur G, Sinha M, Gupta R. Postpartum Vaginal Stenosis Due to Chemical Vaginitis. J Clin Diagn Res. 2016;10(5):3-4.
3. Kim HM, Bae JY, Cho YJ, Kim MJ, Cha HH, Seong WJ. Vaginal adhesions in a woman with the history of dystocia. Obstet Gynecol Sci. 2014;57(2):180.

4. Damast S, Jeffery DD, Son CH, Hasan Y, Carter J, Lindau ST, et al. Literature Review of Vaginal Stenosis and Dilator Use in Radiation Oncology. Pract Radiat Oncol. 2019;9(6):479-91.

5. Salgado CJ, Chim H, Skowronski PP, Oeltjen J, Rodriguez M, Mardini S. Reconstruction of acquired defects of the vagina and perineum. Semin Plast Surg. 2011;25(2):155-62.

6. Mirabeau-Beale K, Hong TS, Niemierko A, Ancukiewicz M, Blaszkowsky LS, Crowley EM, et al. Clinical and treatment factors associated with vaginal stenosis after definitive chemoradiation for anal canal cancer. Pract Radiat Oncol. 2015;5(3):113-8.

7. Arowojolu AO, Okunlola MA, Adekunle AO, Ilesanmi AO. Three decades of acquired gynaetresia in Ibadan: clinical presentation and management. J Obstet Gynaecol. 2001;21(4):375-8.

8. Okeke T, Anyaehie U, Ezenyeaku C. An overview of female genital mutilation in Nigeria. Ann Med Health Sci Res. 2012;2(1):70-3.

9. Fowler JA, Goodman GP, Evans JM, Schober JM. Long-term Vaginal Sequelae Secondary to Pediatric Pelvic Fracture. J Pediatric Adolescent Gynecol. 2009;22(1):15-9.

10. Ganapathy R, Bardis NS, Lamont RF. Secondary repair of the perineum following childbirth. J Obstet Gynaecol. 2008;28(6):608-13.

11. Brand AH, Bull CA, Cakir B. Vaginal stenosis in patients treated with radiotherapy for carcinoma of the cervix. Int J Gynecol Cancer. 2006;16:288-93.

12. Bahng AY, Dagan A, Bruner DW, Lin LL. Determination of prognostic factors for vaginal mucosal toxicity associated with intravaginal highdose rate brachytherapy in patients with endometrial cancer. Int J Radiat Oncol Biol Phys. 2012;82:667-73.

13. Betalli P, De Corti F, Minucci D, Mazzarotto R, Meneghini L, Bisogno G, et al. Successful topical treatment with mitomycin-C in a female with postbrachytherapy vaginal stricture. Pediatric Blood Cancer. 2008;51(4):550-2.

14. Yanai N, Shufaro Y, Or R, Meirow D. Vaginal outflow tract obstruction by graft-versus-host reaction. Bone Marrow Transplantation. 1999;24(7):811-2.

15. Tullington JE, Blecker N. Pelvic Trauma. In: StatPearls. Treasure Island (FL): StatPearls Publishing. 2021.

16. Miles T, Johnson N. Vaginal dilator therapy for women receiving pelvic radiotherapy. Cochrane Database Syst Rev. 2010;(9):CD007291.

Cite this article as: Patel S, Patel S, Bhadana P, Shetty R. Post-traumatic high vaginal stricture and hematocolpos impersonating vaginal septum in adolescent girl: a case report. Int J Reprod Contracept Obstet Gynecol 2022;11:983-5. 